\title{
The association of aggressive and chronic periodontitis with systemic manifestations and dental anomalies in a jordanian population: a case control study
}

\author{
Khansa T Ababneh ${ }^{1 *}$, Anas H Taha', Muna S Abbadi ${ }^{1}$, Jumana A Karasneh², Yousef S Khader ${ }^{3}$
}

\begin{abstract}
Background: The relationship between dental anomalies and periodontitis has not been documented by earlier studies. Although psychological factors have been implicated in the etiopathogenesis of periodontitis, very little information has so far been published about the association of anxiety and depression with aggressive periodontitis. The aim of this study was to investigate the association of chronic periodontitis and aggressive periodontitis with certain systemic manifestations and dental anomalies.
\end{abstract}

Methods: A total of 262 patients (100 chronic periodontitis, 81 aggressive periodontitis and 81 controls), attending the Periodontology clinics at Jordan University of Science and Technology, Dental Teaching Centre) were included. All subjects had a full periodontal and radiographic examination to assess the periodontal condition and to check for the presence of any of the following dental anomalies: dens invaginatus, dens evaginatus, congenitally missing lateral incisors or peg-shaped lateral incisors. Participants were interrogated regarding the following: depressive mood, fatigue, weight loss, or loss of appetite; and their anxiety and depression status was assessed using the Hospital Anxiety and Depression (HAD) scale.

Results: Patients with aggressive periodontitis reported more systemic symptoms (51\%) than the chronic periodontitis (36\%) and control (30\%) patients ( $p<0.05$ ). Aggressive periodontitis patients had a higher tendency for both anxiety and depression than chronic periodontitis and control patients. Dental anomalies were significantly $(p<0.05)$ more frequent among both of chronic and aggressive periodontitis patients (15\% and 16\%, respectively), compared to controls.

Conclusion: In this group of Jordanians, systemic symptoms were strongly associated with aggressive periodontitis, and dental anomalies were positively associated with both aggressive and chronic periodontitis.

\section{Background}

Periodontitis is a multifactorial disease that involves infection and inflammation of the supporting periodontal tissues leading to their destruction [1]. This paper focuses on two types of periodontitis: chronic periodontitis (CP) and aggressive periodontitis (AP) and their association with certain dental anomalies and psychological stress. Page and colleagues in 1983 [2] have

\footnotetext{
* Correspondence: KTABABNEH@HOTMAIL.COM

'Division of Periodontology, Department of Preventive Dentistry, Faculty of Dentistry, Jordan University of Science and Technology, Jordan

Full list of author information is available at the end of the article
}

reported that rapidly progressive periodontitis (RPP, currently termed generalized AP) progresses in alternate phases of disease activity and quiescence. They reported that the active phase of RPP is associated with systemic manifestations such as depression, malaise, weight loss and loss of appetite in some individuals.

Numerous diseases of the dentition exist that may involve the crowns or roots of teeth so that the size, shape or number of teeth may be affected. Dens invaginatus is an uncommon developmental malformation that shows a wide spectrum of anatomic variations [3]. It is believed that it arises from infolding of the dental 
papilla or the distortion of the enamel organ during tooth development [4-6]. The reported prevalence of dens invaginatus ranges between 0.04 to $10 \%$ [7]. The most affected permanent teeth are the maxillary lateral incisors, frequently bilateral followed by central incisors, canines, premolars and molars [8]. Clinicians most commonly use the classification proposed by Oehlers (1957) [5] which classifies dens invaginatus into:

- Type I: an enamel-lined invagination within the crown and not extending beyond the cementoenamel junction (CEJ).

- Type II: the enamel invagination into the root, beyond the CEJ, ending as a blind sac.

- Type III: the extension of the enamel-lined invagination through the root to form an additional apical or lateral foramen; usually, there is no direct communication with the pulp.

Dens evaginatus or talon cusp is a relatively rare odontogenic anomaly arising during tooth morphodifferentiation [9]. The accessory cusp varies in size, shape, length and mode of attachment to crown. It ranges from an enlarged cingulum to a large, well-delineated cusp [10]. It is usually associated with the palatal aspects of the maxillary anterior teeth [11], but may also be present on the occlusal aspects of posterior teeth, especially in people of Asian origin [12].

Peg (conical)-shaped maxillary lateral incisors are relatively common dental anomalies [13-16], that may occur in healthy individuals or as part of other diseases such as Down's syndrome [17]. In their study on Jordanian dental students, Albashaireh \& Khader (2006) [15] reported that the prevalence of peg-shaped lateral incisors was $2.3 \%$.

Hypodontia, the congenital absence of teeth, has been classified into two classes: syndromic, and nonsyndromic, depending on the cause of hypodontia [18]. The upper lateral incisors and second premolars are the most frequently affected teeth [19]. A 5.5\% prevalence of hypodontia has been reported in Jordan [15].

The aims of this study were to examine the association of certain systemic manifestations with both AP and $\mathrm{CP}$, to assess the anxiety and depression status in both types of periodontitis using the Hospital Anxiety and Depression (HAD) scale and to explore the association of $\mathrm{CP}$ and AP with certain dental anomalies. To the best of our knowledge, and based on extensive Medline search, the association between AP/CP and dental anomalies such as dens invaginatus, dens evaginatus, peg-shaped and missing lateral incisors has never been reported in the literature.

\section{Methods}

This investigation was undertaken with the understanding and consent of each participating subject and has been conducted in full accordance with ethical principles of the World Medical Association Declaration of Helsinki http://www.wma.net/en/30publications/10policies/b3/index.html. The study has been independently reviewed and approved by The Ethical Review Board, Jordan University of Science and Technology (JUST). Written consent forms for interview and examination were signed by all participants or the parents of participants under the age of 18 years. The study population of this case-control study consisted of 262 individuals and included $100 \mathrm{CP}$ cases, $81 \mathrm{AP}$ cases and 81 controls. There were 125 males and 137 females with an age range of 14-71 years and a mean age of $31.3( \pm 11.4 \mathrm{SD})$ years. Clinical examination was performed in the Periodontology clinic, JUST Dental Teaching Centre. The study included systemically healthy individuals who have not received any periodontal treatment in the last three months prior to examination. Individuals with diabetes mellitus or blood disorders, patients on any long-term medications, pregnant women, patients with previous or ongoing orthodontic treatment and children under the age of 14 years were excluded from the study.

The participants' demographic and socioeconomic information were recorded on a special examination form and all participating subjects were asked whether they often experienced any of the following systemic symptoms: fatigue (without an obvious cause), loss of appetite, weight loss and depressive mood. The emotional status was further assessed for all subjects using the HAD Scale [20] (Figure 1). This scale is a selfassessment instrument that has been designed to detect anxiety and depression in medical outpatients [20]. The HAD scale consists of 14 statements (7 for anxiety, designated as "A" and 7 for depression, designated as "B"), with 4 possible responses for each statement. Each response is scored from $0-4$ points. The minimum subscore for each category ("A" or " $\mathrm{B}$ ") is zero and the maximum subscore is 21 . According to the subscore of the HAD scale, the participants were divided into three groups, as recommended by the authors [20]; those who scored $\leq 7$ were considered to be free of anxiety or depression, those who scored 8-10 were considered to have doubtful anxiety or depression and those whose subscore was $\geq 11$ were considered to have anxiety or depression.

For each subject, full mouth periodontal examination was carried out by one of three examiners (AHT, MSA and KTA). The periodontal examination included measurement of Clinical Attachment Level (CAL) and the plaque index (PI) of Silness and Löe [21]. For measurement of CAL, each tooth was examined by "walking" the periodontal probe around the whole circumference of the tooth; third molars and remaining roots were excluded. CAL was measured at six sites per tooth 


\begin{tabular}{|c|c|c|}
\hline Statement & Response & Points \\
\hline \multirow[t]{4}{*}{ I feel tense or "wound up" } & most of the time & $3[\mathrm{~A}]$ \\
\hline & a lot of the time & 2 \\
\hline & from time to time, occasionally & 1 \\
\hline & not at all & 0 \\
\hline \multirow{4}{*}{ I still enjoy the things I used to enjoy } & definitely as much & $0[\mathrm{D}]$ \\
\hline & not quite as much & 1 \\
\hline & only a little & 2 \\
\hline & hardly at all & 3 \\
\hline \multirow[t]{4}{*}{ I get a sort of frightened feeling as if something awful is about to happen } & very definitely and quite badly & $3[\mathrm{~A}]$ \\
\hline & yes, but not too badly & 2 \\
\hline & a little, but it doesn't worry me & 1 \\
\hline & not at all & 0 \\
\hline \multirow[t]{4}{*}{ I can laugh and see the funny side of things } & as much as I always could & $0[\mathrm{D}]$ \\
\hline & not quite so much now & 1 \\
\hline & definitely not so much now & 2 \\
\hline & not at all & 3 \\
\hline \multirow[t]{4}{*}{ Worrying thoughts go through my mind } & a great deal of the time & $3[\mathrm{~A}]$ \\
\hline & a lot of the time & 2 \\
\hline & from time to time but not too often & 1 \\
\hline & only occasionally & 0 \\
\hline \multirow{4}{*}{ I feel cheerful } & not at all & $3[\mathrm{D}]$ \\
\hline & not often & 2 \\
\hline & sometimes & 1 \\
\hline & most of the time & 0 \\
\hline \multirow[t]{4}{*}{ I can sit at ease and feel relaxed } & definitely & $0[\mathrm{~A}]$ \\
\hline & usually & 1 \\
\hline & not often & 2 \\
\hline & not at all & 3 \\
\hline \multirow[t]{4}{*}{ I feel as if I am slowed down } & nearly all the time & $3[\mathrm{D}]$ \\
\hline & very often & 2 \\
\hline & sometimes & 1 \\
\hline & not at all & 0 \\
\hline \multirow{4}{*}{ I get a sort of frightened feeling, like "butterflies" in the stomach } & not at all & $0[\mathrm{~A}]$ \\
\hline & occasionally & 1 \\
\hline & quite often & 2 \\
\hline & very often & 3 \\
\hline \multirow{4}{*}{ I have lost interest in my appearance } & definitely & $3[\mathrm{D}]$ \\
\hline & I don't take so much care as I should & 2 \\
\hline & I may not take quite as much care & 1 \\
\hline & I take just as much care as ever & 0 \\
\hline \multirow[t]{4}{*}{ I feel restless as if I have to be on the move } & very much indeed & $3[\mathrm{~A}]$ \\
\hline & quite a lot & 2 \\
\hline & not very much & 1 \\
\hline & not at all & 0 \\
\hline \multirow[t]{4}{*}{ I look forward with enjoyment to things } & as much as ever I did & $0[\mathrm{D}]$ \\
\hline & rather less than I used to & 1 \\
\hline & definitely less than I used to & 2 \\
\hline & hardly at all & 3 \\
\hline \multirow[t]{4}{*}{ I get sudden feelings of panic } & very often indeed & $3[\mathrm{~A}]$ \\
\hline & quite often & 2 \\
\hline & not very often & 1 \\
\hline & not at all & 0 \\
\hline \multirow[t]{4}{*}{ I can enjoy a good book or radio or TV program } & often & $0[\mathrm{D}]$ \\
\hline & sometimes & 1 \\
\hline & not often & 2 \\
\hline & very seldom & 3 \\
\hline \multicolumn{3}{|l|}{ A: Anxiety; D: Depression } \\
\hline \multicolumn{3}{|l|}{$\begin{array}{l}\text { Anxiety subscore = Sum of points for the } 7 \text { "A" items } \\
\text { Depression subscore = Sum of points for the } 7 \text { "D" items) }\end{array}$} \\
\hline Figure 1 A copy of the Hospital Anxiety and Depression (HAD) & & \\
\hline
\end{tabular}

(mesio-, mid-, and disto-buccal; mesio-, mid-, and distolingual/palatal). Inter-examiner reliability was calculated using alpha statistics with regard to probing depth and CAL on 16 quadrants. Diagnosis of CP and AP was based on CAL values and confirmed radiographically using intra-oral periapical and bitewing radiographs. Periodontitis was defined as the presence of attachment loss $(\mathrm{CAL})>2 \mathrm{~mm}$ on more than one tooth. For all 
participants bitewing radiographs were taken for posterior teeth and pariapical radiographs were taken for anterior teeth to detect the presence and pattern of alveolar bone loss and confirm (or exclude) the presence of periodontitis. To differentiate between $\mathrm{CP}$ and AP, the clinical findings including gingival condition, CAL, the severity and (to a lower extent) the pattern of bone loss, together with the subject's age were used as diagnostic criteria. When the subject had CAL $>2 \mathrm{~mm}$ around at least two teeth, one of which was a first molar, or when attachment loss was observed around first molars and/ or incisors that exhibited bone loss at an early age (i.e. $<45$ years), especially were the characteristic arc-shaped defect(s) was/were detectable on radiographs, the case was diagnosed as AP. Inconsistence between the amount of plaque deposits and amount of periodontal destruction (whenever present), and positive family history further confirmed the diagnosis of AP. On the other hand, CP was diagnosed when CAL $>2 \mathrm{~mm}$ around at least two teeth, usually in older age groups (i.e. $>45$ years). Young individuals with slight attachment and bone loss in whom plaque deposits were consistent with the amount of destruction were diagnosed as having CP. Cases where there was uncertainty in the diagnosis of AP or CP were not included in this study.

The investigated dental anomalies included dens invaginatus, dens evaginatus, congenitally missing and peg shaped lateral incisors. Congenitally missing teeth were recorded after verifying their congenital absence by the participants and their absence was confirmed using periapical radiographs. The presence of peg-shaped lateral incisors was noted and all teeth were examined both clinically and radiographically for the presence of dens evaginatus and dens invaginatus. Dens evaginatus cases were classified according to Oehlers (1957) [5].

\section{Statistical Analysis}

All variables were entered into a personal computer, and the Statistical Package for Social Sciences (SPSS Version 11, Chicago, Illinois) software was used for data processing and analysis. Frequency distribution and cross-tabulation were produced. Mean values and standard deviation were calculated and Chi-square test was used. Differences were considered significant when $\mathrm{p}$ was < 0.05 .

\section{Results}

The Cronbach alpha coefficient was 0.94 for CAL, indicating excellent agreement between the examiners.

The mean CAL value for CP cases was $2.17 \mathrm{~mm}( \pm$ 1.53 SD), whereas the mean CAL value for AP cases was $2.76 \mathrm{~mm}( \pm 1.77 \mathrm{SD})$. The control subjects exhibited no attachment loss (mean CAL $=0 \mathrm{~mm}$ ) and no radiographic evidence of alveolar bone loss.

\section{Sociodemographic Characteristics}

As shown in Table 1, the highest proportion of $\mathrm{CP}$ patients were males, aged between 36 to 45 years, employed but with a low income and had up to high school education (i.e. $\leq 12$ years). CP subjects and controls were significantly different with regard to age, occupation, place of residence and education. The highest percentage of AP subjects were young ( $\leq 25$ years), were females, were unemployed, had a low income, lived in urban areas and had received up to high school education. Members of the AP group were significantly different from controls with respect to age, gender, occupation, income and education. When the CP and AP groups were compared, statistically significant differences were found between both groups with regard to age, gender, occupation, place of residence and education (Table 1).

The control sample consisted of 81 systemically healthy, periodontitis-free Jordanian subjects; 45 males and 36 females, with an age range of 14-37 years, and a mean age of 22.2 years $( \pm S D)$, in whom no clinical or radiographic evidence of attachment or bone loss was present at any site. The age of the controls was not restricted to 37 years, but it was virtually impossible to find periodontally healthy individuals aged 40 years or above.

\section{Systemic Manifestations}

About $51 \%$ of AP patients reported that they often experienced one or more systemic symptoms (mostly fatigue and depressive mood), which they could not relate to disease or to external factors. A lower percentage of CP cases (36\%) and controls (about 29\%) reported the presence of such symptoms. The frequency of systemic manifestations was significantly greater in AP subjects than controls $(p=0.019)$. No significant differences were detected in the frequency of systemic symptoms between CP cases and controls $(p=0.7)$. However, marginally significant difference was observed between CP and AP cases $(p=0.059)$. Table 2 shows the differential distribution of the systemic manifestations reported by the study population. The most commonly reported systemic complaint by the 3 groups was fatigue, followed by depressive mood. Although depressive mood was more frequently reported by AP patients than the other 2 groups, the difference was not statistically significant.

\section{Anxiety and Depression using the HAD Scale}

The anxiety and depression scores were summed independently to obtain an "anxiety score" and a "depression score" for each subject. Table 3 shows the numbers and percentages of individuals in each category of HAD scale scores. The group of highest percentage in this 
Table 1 Socio-demographic characteristics of the study population

\begin{tabular}{|c|c|c|c|c|c|c|c|}
\hline \multicolumn{2}{|c|}{ Variables } & \multirow{2}{*}{$\begin{array}{c}\text { CP } \\
\text { No (\%) }\end{array}$} & \multirow{2}{*}{$\begin{array}{c}\text { AP } \\
\text { No (\%) }\end{array}$} & \multirow{2}{*}{$\begin{array}{c}\text { Controls } \\
\text { No (\%) }\end{array}$} & \multirow[t]{2}{*}{$P$-value ${ }^{a}$} & \multirow[t]{2}{*}{ P-value ${ }^{b}$} & \multirow[t]{2}{*}{ P-value ${ }^{c}$} \\
\hline & & & & & & & \\
\hline \multirow[t]{5}{*}{ Age (Yrs) } & $\leq 25$ & $10(10)$ & $31(38.3)$ & $63(77.8)$ & $<0.0001$ & $<0.0001$ & $<0.0001$ \\
\hline & $26-35$ & $24(24)$ & $25(30.9)$ & $13(16)$ & & & \\
\hline & $36-45$ & $34(34)$ & $24(29.6)$ & $5(6.2)$ & & & \\
\hline & $\geq 46$ & $32(32)$ & $1(1.2)$ & - & & & \\
\hline & Mean & 39.9 & 29.8 & 22.2 & & & \\
\hline \multirow[t]{2}{*}{ Gender } & Female & $45(45)$ & $57(70.4)$ & $35(43.2)$ & 0.464 & $<0.0001$ & $<0.0001$ \\
\hline & Male & $55(55)$ & $24(29.6)$ & $46(56.8)$ & & & \\
\hline \multirow[t]{3}{*}{ Occupation } & Student & $6(6)$ & $17(21)$ & $55(67.9)$ & $<0.0001$ & $<0.0001$ & 0.001 \\
\hline & Employed & $58(58)$ & $28(34.6)$ & $21(25.9)$ & & & \\
\hline & Unemployed & $36(36)$ & $36(44.4)$ & $5(6.2)$ & & & \\
\hline \multirow[t]{2}{*}{ Income (JOD) $)^{d}$} & $\leq 350$ & $84(84)$ & 70 (86.4) & $59(72.8)$ & 0.067 & 0.032 & 0.65 \\
\hline & $>350$ & $16(16)$ & $11(13.6)$ & $22(27.2)$ & & & \\
\hline \multirow[t]{2}{*}{ Residence } & Urban & $50(50)$ & $53(65.4)$ & $63(77.8)$ & $<0.0001$ & 0.058 & 0.037 \\
\hline & Rural & $50(50)$ & $28(34.6)$ & $18(22.2)$ & & & \\
\hline \multirow[t]{2}{*}{ Education } & $\leq$ High school & $67(67)$ & $42(51.9)$ & $25(30.9)$ & $<0.0001$ & 0.005 & 0.038 \\
\hline & $>$ High school & 33 (33) & $39(48.1)$ & $56(69.1)$ & & & \\
\hline
\end{tabular}

${ }^{a} \mathrm{CP}$ vs. Controls; Chi-square test

${ }^{b}$ AP vs. Controls; Chi-square test

${ }^{c} \mathrm{CP}$ vs. AP; Chi-square test

${ }^{\mathrm{d}}$ Monthly in Jordanian Dinars $=\$ 1.41$

study scored 7 or less for both anxiety and depression. While almost equal proportions of AP (31\%) and CP (32\%) patients had doubtful anxiety, a much lower proportion of controls (14\%) had doubtful anxiety. However, a higher percentage of patients with AP (31\%) had definite anxiety than CP (21\%) and controls (22\%). Concerning depression scores, a higher percentage (26\%) of AP cases had doubtful depression as well as definite depression (11\%) than CP cases and controls. Table 3 also demonstrates that more AP patients (31\%) had anxiety than depression (11\%).

The highest mean of anxiety and depression HAD scale scores (Table 3) was found in subjects with AP [8.5 $( \pm 3.4)$ for anxiety and $6.8( \pm 2.9)$ for depression], while the lowest scores were observed in the control group $[7( \pm 3.8)$ for anxiety and $4.8( \pm 3.1)$ for depression]. A statistically significant difference was found when the anxiety $(p=0.039)$ and depression $(p=0.001)$ scores of AP patients were compared to controls. However, no significant differences were found in mean HAD scores by comparing $\mathrm{CP}$ and $\mathrm{AP}$ cases with controls (Table 3).

\section{Dental Anomalies}

Dental anomalies were observed in 28 cases of the study population; in $15 \%$ of CP cases (15 subjects) and in 16\% of AP cases (13 subjects), but were not observed in any of the control subjects (Table 4). All cases of dens invaginatus were observed uni- and bilaterally on the maxillary lateral incisors and were clinically and radiographically type I. All cases of dens evaginatus were small, cusp-like enlargements of the cingulum of maxillary lateral incisors and did not interfere with occlusion. Among AP cases (Table 5), 8 patients (9.9\%) had dens invaginatus, one

Table 2 differential distribution of systemic manifestations

\begin{tabular}{llccccc}
\hline Systemic Manifestation & CP & AP & Controls & & \multicolumn{2}{c}{ P-values } \\
\hline Fatigue & No (\%) & No $(\%)^{\mathbf{b}}$ & No (\%) & CP vs. Control & AP vs. Control & CP vs. AP \\
Loss of appetite & $21(21)$ & $13(16.0)$ & $15(18.5)$ & 0.405 & 0.851 & 0.229 \\
Weight loss & $2(2)$ & $6(7.4)$ & $3(3.7)$ & 1.000 & 0.508 & 1.000 \\
Depressive mood & $2(2)$ & $2(2.5)$ & $3(3.7)$ & 1.000 & 0.289 & 1.000 \\
Total & $5(5)$ & $9(11.1)$ & $3(3.7)$ & 0.727 & 0.146 & $\mathbf{0 . 0 1 9}$ \\
\hline
\end{tabular}

\footnotetext{
a Percentage out of a total of 100

b Percentage out of a total of 81

c Percentage out of a total of 81
} 
Table 3 HAD Scale for Anxiety and Depression among the study population

\begin{tabular}{|c|c|c|c|c|c|}
\hline \multicolumn{2}{|c|}{ Variables } & \multirow{2}{*}{$\begin{array}{c}\text { CP } \\
\text { No (\%) }\end{array}$} & \multirow{2}{*}{$\begin{array}{c}\text { AP } \\
\text { No (\%) } \\
\end{array}$} & \multirow{2}{*}{$\begin{array}{l}\text { Controls } \\
\text { No (\%) }\end{array}$} & \multirow{2}{*}{$\begin{array}{c}P \\
\text { values }\end{array}$} \\
\hline & & & & & \\
\hline \multirow[t]{5}{*}{ Anxiety } & $\begin{array}{l}\leq \mathbf{7} \text { (Not } \\
\text { present) }\end{array}$ & $47(47)$ & $31(38)$ & $52(64)$ & $0.49^{a}$ \\
\hline & 8-10 (Doubtful) & $32(32)$ & $25(31)$ & $11(14)$ & $0.039^{\mathrm{b}}$ \\
\hline & $\geq 11$ (Definite) & $21(21)$ & $25(31)$ & $18(22)$ & $0.74^{c}$ \\
\hline & Total & $100(100)$ & $81(100)$ & $81(100)$ & \\
\hline & Mean $( \pm \mathrm{SD})$ & $\begin{array}{c}7.4( \pm \\
3.9)\end{array}$ & $\begin{array}{c}8.5( \pm \\
3.4)\end{array}$ & $7( \pm 3.8)$ & \\
\hline \multirow[t]{5}{*}{ Depression } & $\begin{array}{l}\leq \mathbf{7} \text { (Not } \\
\text { present) }\end{array}$ & $68(68)$ & $51(63)$ & $67(83)$ & $0.17^{\mathrm{d}}$ \\
\hline & 8-10 (Doubtful) & $23(23)$ & $21(26)$ & $10(12)$ & $0.001^{e}$ \\
\hline & $\geq 11$ (Definite) & $9(9)$ & $9(11)$ & $4(5)$ & $0.22^{f}$ \\
\hline & Total & $100(100)$ & $81(100)$ & $81(100)$ & \\
\hline & Mean $( \pm S D)$ & $\begin{array}{c}5.8( \pm \\
3.5)\end{array}$ & $\begin{array}{c}6.8( \pm \\
2.9)\end{array}$ & $\begin{array}{c}4.8( \pm \\
3.1)\end{array}$ & \\
\hline
\end{tabular}

${ }^{a}$ CP vs. Controls (Chi-square test)-Anxiety

${ }^{b}$ AP vs. Controls (Chi-square test) -Anxiety

${ }^{\mathrm{C}} \mathrm{CP}$ vs. AP (Chi-square test) -Anxiety

${ }^{d}$ CP vs. Controls (Chi-square test) -Depression

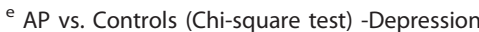

${ }^{f}$ CP vs. AP (Chi-square test) -Depression

(1.2\%) had dens evaginatus, 2 (2.46\%) had bilateral pegshaped lateral incisors and 2 patients $(2.46 \%)$ had a congenitally missing upper lateral incisor. Among CP cases, 6 patients $(6 \%)$, had dens invaginatus, 2 (2\%) had dens evaginatus and 7 (7\%) had unilateral congenitally missing teeth (2 lower second premolars and 5 maxillary lateral incisors). Both AP and CP were significantly more associated with dental anomalies than controls $(p<0.05)$, while the difference between the two periodontitis groups was not significant $(p=0.72)$. Furthermore, the disease groups did not significantly differ from controls or from each other when compared for each of the dental anomalies separately $(p>0.05)$.

\section{Discussion}

The distribution of chronic and aggressive periodontitis found in this study followed the general patterns reported by others [22-24]. The highest percentage of CP patients were older ( $>35$ years) than the highest
Table 5 Dental Anomalies in CP and AP

\begin{tabular}{|c|c|c|c|c|}
\hline \multirow[t]{2}{*}{ Dental Anomaly } & \multirow[t]{2}{*}{ Site } & $\mathrm{CP}$ & \multirow{2}{*}{$\begin{array}{c}\text { AP } \\
\text { No }(\%)^{b}\end{array}$} & \multirow{2}{*}{$\begin{array}{l}\text { Controls } \\
\text { No }(\%)^{c}\end{array}$} \\
\hline & & $\begin{array}{l}\text { No } \\
(\%)^{a}\end{array}$ & & \\
\hline Dens invaginatus & Upper incisors & $6(6)$ & $8(9.9)$ & $0(0)$ \\
\hline Dens evaginatus & Upper incisors & $2(2)$ & $1(1.2)$ & $0(0)$ \\
\hline $\begin{array}{l}\text { Peg-shaped lateral } \\
\text { incisors }\end{array}$ & $\begin{array}{l}\text { Upper lateral } \\
\text { incisors }\end{array}$ & $0(0)$ & $2(2.46)$ & $0(0)$ \\
\hline \multirow[t]{2}{*}{$\begin{array}{l}\text { Congenitally missing } \\
\text { teeth }\end{array}$} & $\begin{array}{l}\text { Upper lateral } \\
\text { incisors }\end{array}$ & 7 & $2(2.46)$ & $0(0)$ \\
\hline & $\begin{array}{l}\text { lower second } \\
\text { premolars }\end{array}$ & 2 & $0(0)$ & $0(0)$ \\
\hline
\end{tabular}

${ }^{a}$ Out of 1 total of 100

${ }^{\mathrm{b}}$ Out of a total of 81

c Out of a total of 81

percentage of AP patients ( $<25$ years). This confirms that AP is usually manifested earlier in life in susceptible individuals. While CP was distributed almost equally between males and females in this study, a greater proportion of AP patients were females. Surveys of periodontal conditions usually show that adult males are at a higher risk of developing CP than females [25]. This difference may be a reflection of better oral hygiene practices and more utilization of oral health care services among females rather than inherent differences between males and females regarding susceptibility to CP [26]. We found that the frequency of both forms of periodontitis was significantly lower in students as compared to employed and unemployed subjects. Socioeconomic level is a good marker of various risk factors for periodontitis such as oral hygiene, provision of dental care and behaviors. Previous studies have documented differences in periodontal health based on socioeconomic status (SES) factors, such as income and education, showing that lower SES was associated with increased risk to periodontitis [27]. However, education is currently believed to have a greater effect than income on the level of periodontitis in the population [28].

In this investigation certain systemic manifestations such as fatigue, loss of appetite, weight loss and depressive mood were investigated in relation to $\mathrm{CP}$ and $\mathrm{AP}$. A significant proportion of patients diagnosed with AP reported that they experienced (one or more of these) systemic manifestations with the most frequently reported symptoms being fatigue and depressive mood.

Table 4 Dental Anomalies in Cases and Controls

\begin{tabular}{cccccc}
\hline Dental Anomalies & CP & AP & Controls & & P-values $^{\text {a }}$ \\
\hline Yes & No (\%) & No $(\%)$ & No $(\%)$ & CP vs. Controls & AP vs. Controls \\
No & $15(15)$ & $13(16)$ & $0(0)$ & 0.004 & 0.003 \\
Total & $85(85)$ & $68(84)$ & $81(100)$ & & 0.72 \\
\hline
\end{tabular}

\footnotetext{
${ }^{a}$ Chi-square test
} 
These findings are in accordance with those of Page et al. [2] who suggested that RPP (generalized AP) progresses in phases of activity and quiescence and that the active phase of RPP in a proportion of individuals involves systemic manifestations such as depression, general malaise, weight loss, and loss of appetite [2]. We have also observed that the frequency of these systemic manifestations is significantly greater in AP patients than in controls or CP patients (marginal significance). Evaluation of the anxiety and depression status of the participants in this study, using the HAD scale, demonstrated that subjects diagnosed with AP exhibited significantly more anxiety and depression, compared to CP patients and controls. It would be of interest to know how periodontitis (especially AP) is related to anxiety and depression. The bulk of literature has investigated the effect of psychological stress on periodontitis, but the effect of periodontitis on the psychological condition has not been the focus of much interest. The present study demonstrates mere association between periodontitis and both of anxiety and depression, and future longitudinal and multidisciplinary work is needed to shed light on this point. Furthermore, in the present study individuals with AP tended to score higher for anxiety than for depression. Anxiety in patients with AP may arise, in part, from their concern of losing teeth at a young age. It is also worth noting that most AP patients were unemployed, had a low income and had only (up to) high school education; unemployment, low income and education may give rise to instabilities in life and contribute to anxiety. However, it is not clear from the present results whether the presence of periodontitis and the poor prognosis of the dentition in this group of individuals have predisposed to anxiety and depression, or these psychological symptoms are true components of the disease (AP and possibly $\mathrm{CP}$ ) as Page and colleagues [2] have suggested, and further studies are necessary to investigate this association.

Several dental anomalies were investigated in the present study including dens invaginatus, dens evaginatus, pegshaped lateral incisors and congenitally missing lateral incisors. Interestingly, the dental anomalies investigated in this study were observed only in subjects with $\mathrm{CP}$ and AP, in contrast to controls where none of the dental anomalies investigated was present. Furthermore, the frequency of dens invaginatus observed among the AP (16\%) and CP (15\%) groups was significantly higher than that reported for the general population in Jordan (2.95\%) [27]. It is believed that dental malformations are genetically determined because they are highly reproducible in shape, show predilection for some racial groups and often occur together [12]. The development of teeth is believed to be under strict genetic control, which determines the positions, numbers and shapes of different teeth [19].
Furthermore, dental anomalies, such as peg-shaped lateral incisors for example, are well documented components of numerous systemic diseases and syndromes, such as Down's syndrome [17], Witkop tooth and nail syndrome [28], Saethre-Chotzen syndrome [29], submucous cleft palate [30] and Hypohidrotic ectodermal dysplasia [31]. As the genetic basis for various dental anomalies is gradually being revealed [9], it is simultaneously becoming clearer that predisposition to various types of periodontitis is related to genetic polymorphisms in genes encoding certain cytokines and other components of the immune system, such as IL-1 [32] and IL-10 [33].

Therefore, it seems logical to postulate that certain dental anomalies may be components of AP and $\mathrm{CP}$ in some individuals resulting from specific, possibly related, genetic polymorphisms. This study, however, shows mere association and cannot confirm or exclude such an assumption. Genetic and large scale epidemiological studies, designed to investigate the association of AP and $\mathrm{CP}$ with individual dental anomalies are needed.

\section{Conclusions}

It is concluded that the systemic manifestations of fatigue, depressive mood, loss of appetite and weight loss were strongly associated with AP. The dental anomalies dens invaginatus, dens evaginatus, peg-shaped and congenitally missing lateral incisors were found to be associated with aggressive and chronic periodontitis. The presence of these dental anomalies should encourage clinicians to perform thorough periodontal examination, and patients with aggressive periodontitis may be candidates for referral to professional psychological care.

\section{List of Abbreviations}

AP: Aggressive Periodontitis; CAL: Clinical Attachment Level; CEJ: Cementoenamel Junction; CP: Chronic Periodontitis; HAD scale: Hospital Anxiety and Depression scale; IL-1: Interleukin 1; IL-10: Interleukin 10; JOD: Jordanian Dinar; PI: Plaque Index; RPP: Rapidly Progressive Periodontitis; SES Socioeconomic Status.

\section{Acknowledgements}

The authors wish to thank Jordan University of Science and Technology for sponsoring this work with a grant through the Deanship of Scientific Research. Special thanks are due to the Faculty of Dentistry and JUST Dental Teaching Centre, Irbid, Jordan for facilitating the clinical and radiographic examination of the participants in this study. We thank Mrs. Sumayya Khamaiseh and Mrs. Yasmin Jaradat for their assistance during data collection.

\section{Author details}

'Division of Periodontology, Department of Preventive Dentistry, Faculty of Dentistry, Jordan University of Science and Technology, Jordan. ${ }^{2}$ Division of Oral Medicine, Department of Oral surgery, Oral Medicine, Oral Pathology and Radiology, Faculty of Dentistry, Jordan University of Science and Technology, Jordan. ${ }^{3}$ Community Medicine \& Public Health, Faculty of Medicine, Jordan University of science and Technology, Jordan.

\section{Authors' contributions}

KTA put forward the research design, supervised and participated in data collection and wrote the manuscript. Both of AHT and MSA each carried out 
data collection and patient examination, and contributed to writing of the manuscript. JAK put forward the research design and participated in data analysis. YSK carried out the statistical analysis. All authors have read and approved the manuscript.

\section{Competing interests}

The authors declare that they have no competing interests.

Received: 17 October 2010 Accepted: 29 December 2010 Published: 29 December 2010

\section{References}

1. Kinane DF: Causation and pathogenesis of periodontal disease. Periodontology 2000 2001, 25:8-20.

2. Page RC, Altman LC, Ebersole JL, Vandesteen GE, Dahlberg WH, Williams BL, Osterberg SK: Rapidly progressive periodontitis. A distinct clinical condition. J Perio 1983, 54:197-209.

3. Silberman A, Cohenca N, Simon $\mathrm{JH}$ : Anatomical redesign for the treatment of dens invaginatus type III with open apexes: a literature review and case presentation. J Am Dent Assoc 2006, 137:180-185.

4. Kronfeld R: Dens in dente. J Dent Res 1934, 14:49-66.

5. Oehlers FA: Dens invaginatus, part I: variations of the invagination process and association with anterior crown forms. Oral Surg Oral Med Oral Pathol 1957, 10:1204-1218.

6. Oehlers FA: The radicular variety of dens invaginatus. Oral Surg Oral Med Oral Pathol 1958, 11:1251-1260.

7. Hovland EJ, Block RM: Nonrecognition and subsequent endodontic treatment of dens invaginatus. J Endod 1977, 3:360-362.

8. Alani A, Bishop K: Dens invaginatus. Part 1:classification, prevalence and aetiology. Int Endod J 2008, 41:1123-1136.

9. Al-Omari MA, Hattab FN, Darwazeh AM, Dummer PM: Clinical problems associated with unusual cases of talon cusp. Int Endod J 1999, 32:183-190.

10. Hattab FN, Yassin OM, al-Nimri KS: Talon cusp-clinical significance and management: case reports. Quintessence Int 1995, 26:115-120.

11. Lorena SC, Oliveira DT, Odellt EW: Multiple dental anomalies in the maxillary incisor region. J Oral Sci 2003, 45:47-50.

12. Levitan ME, Himel VT: Dens evaginatus: literature review, pathophysiology, and comprehensive treatment regimen. J Endod 2006, 32:1-9.

13. Yonezu T, Hayashi Y, Sasaki J, Machida Y: Prevalence of congenital dental anomalies of the deciduous dentition in Japanese children. Bull Tokyo Dent Coll 1997, 38:27-32.

14. Bäckman B, Wahlin YB: Variations in number and morphology of permanent teeth in 7-year-old Swedish children. Int J Paediatr Dent 2001, 11:11-17.

15. Albashaireh ZS, Khader YS: The prevalence and pattern of hypodontia of the permanent teeth and crown size and shape deformity affecting upper lateral incisors in a sample of Jordanian dental patients. Community Dent Health 2006, 23:239-243.

16. Wu H, Feng $\mathrm{HL}$ : A survey of number and morphology anomalies in permanent teeth of 6453 youths between 17 to 21 years old. Zhonghua Kou Qiang Yi Xue Za Zhi 2005, 40:489-490.

17. Cheng $\mathrm{RH}$, Leung WK, Corbet EF, King NM: Oral health status of adults with Down syndrome in Hong Kong. Spec Care Dentist 2007, 27:134-138.

18. Pemberton TJ, Mendoza G, Gee J, Patel PI: Inherited dental anomalies: a review and prospects for the future role of clinicians. J Calif Dent Assoc 2007, 35:324-326, 328-333.

19. Arte S, Nieminen P, Apajalahti S, Haavikko K, Thesleff I, Pirinen S: Characteristics of incisor-premolar hypodontia in families. J Dent Res 2001, 80:1445-1450.

20. Zigmond AS, Snaith RP: The hospital anxiety and depression scale. Acta Psychiatr Scand 1983, 67:361-370.

21. Silness J, Löe H: Periodontal disease in pregnancy. II. Correlation between oral hygiene and periodontal condition. Acta Odontol Scand 1964, 22:121-135.

22. Pihlstrom BL: Periodontal risk assessment, diagnosis and treatment planning. Periodontology 2000 2001, 25:37-58.

23. Albandar JM, Rams TE: Risk factors for periodontitis in children and young persons. Periodontology 2000 2000, 29:207-222.

24. Borrell LN, Papapanou PN: Analytical epidemiology of periodontitis. J Clin Periodontol 2005, 32:132-158.
25. Albandar JM: Epidemiology and risk factors of periodontal diseases. Dent Clin North Am 2005, 49:517-32, v-vi.

26. Borrell LN, Burt BA, Neighbors HW, Taylor GW: Social factors and periodontitis in an older population. Am J Public Health 2004, 94:748-754

27. Hamasha AA, Alomari QD: Prevalence of dens invaginatus in Jordanian adults. Int Endod J 2004, 37:307-310.

28. Altug-Atac AT, Iseri $\mathrm{H}$ : Witkop tooth and nail syndrome and orthodontics. Angle Orthod 2008, 78:370-380.

29. Marchesi A, Leoni R: Multiple peg-shaped teeth associated with acrocephalosyndactyly. A variant of the Saethre-Chotzen syndrome? A clinical case. Minerva Stomatol 1993, 42:169-172.

30. Helióvaara A, Ranta R, Rautio J: Dental abnormalities in permanent dentition in children with submucous cleft palate. Acta Odontol Scand 2004, 62:129-131.

31. Shigli A, Reddy RV, Hugar SM, Deshpande D: Hypohidrotic ectodermal dysplasia: A unique approach to esthetic and prosthetic management: A case report. J Indian Soc Pedod Prev Dent 2005, 23:31-34.

32. Kornman KS, Crane A, Wang HY, di Giovine FS, Newman MG, Pirk FW, Wilson TG Jr, Higginbottom FL, Duff GW: The interleukin-1 genotype as a severity factor in adult periodontal disease. J Clin Periodontol 1997, 24:72-77.

33. Berglundh T, Donati M, Hahn-Zoric M, Hanson LA, Padyukov L: Association of the -1087 IL 10 gene polymorphism with severe chronic periodontitis in Swedish Caucasians. J Clin Periodontol 2003, 30:249-254.

doi:10.1186/1746-160X-6-30

Cite this article as: Ababneh et al:: The association of aggressive and chronic periodontitis with systemic manifestations and dental anomalies in a jordanian population: a case control study. Head \& Face Medicine 2010 6:30.

\section{Submit your next manuscript to BioMed Central and take full advantage of:}

- Convenient online submission

- Thorough peer review

- No space constraints or color figure charges

- Immediate publication on acceptance

- Inclusion in PubMed, CAS, Scopus and Google Scholar

- Research which is freely available for redistribution

Submit your manuscript a www.biomedcentral.com/submit
Biomed Central 